\title{
Detection of explanation obstacles in scientific texts: the effect of an understanding task vs. an experiment task
}

\author{
Júlia Morgado $^{\mathrm{a}}$, José Otero ${ }^{\mathrm{b}}$, Piedade Vaz-Rebelo ${ }^{\mathrm{c} *}$, Vicente Sanjosé ${ }^{\mathrm{d}}$ and Helena \\ Caldeira $^{\mathrm{c}}$ \\ ${ }^{a}$ High School St. Maria do Olival, Tomar, Portugal; ${ }^{b}$ Department of Physics and \\ Mathematics, University of Alcalá, Alcalá de Henares, Spain; ${ }^{c}$ Faculty of Sciences and \\ Technology, University of Coimbra, Coimbra, Portugal; ${ }^{d}$ ERI-Polibienestar, University of \\ Valencia, Valencia, Spain
}

(Received 14 August 2012; final version received 11 November 2013)

\begin{abstract}
The aim of this study is to analyse the effect of tasks on the detection of explanation obstacles when secondary school students read scientific texts. Students were instructed to read short passages under different task conditions, and to ask questions if necessary. Obstacle detection was operationalised in terms of the type of questions asked by the students. The experiment examined the influence of goals associated with the task of reading to understand a text vs. reading to perform a procedure described by the text (a science experiment). Significantly, more explanation obstacles were found in the understanding condition than in the experiment condition. Scientific text also had an effect on the explanation obstacles detected.
\end{abstract}

Keywords: student questions; reading task; reading goal

\section{Introduction}

Understanding scientific texts is a difficult task for many students (Graesser, León, and Otero 2002). A substantial number of studies have examined variables that influence comprehension of scientific discourse, such as text features, readers' interest, previous knowledge or reading skills (Alexander, Kulikowich, and Schulze 1994; Brincones and Otero 1994; Dee-Lucas and Larkin 1990; Ozuru, Dempsey, and McNamara 2009). This study focuses on incomprehension, rather than comprehension, examining the variables that influence the detection of obstacles to comprehension in scientific texts, and the use of questions to overcome these obstacles.

The contention here is that a focus on incomprehension is important, on the basis of theoretical perspectives that show the relevance of appropriate incomprehension in discourse processing. Models of self-regulated learning emphasise the importance of appropriately monitoring and regulating progress towards a learning goal such as understanding a text (Dunlosky and Metcalfe 2008; Thiede, Wiley, and Griffin 2011). These models describe learning as a process that involves setting a learning goal, monitoring progress towards the goal and regulating study in order to achieve the goal. This involves identifying any discrepancies between the actual learning state and the learning goal. It amounts to being aware of the obstacles to

*Corresponding author. Email: pvaz@mat.uc.pt 
comprehension, then taking steps to solve these comprehension problems, for instance by asking questions.

Individual, text and task variables influence reading comprehension (Snow 2002) and are therefore expected to influence conscious incomprehension as well. This article examines how readers' tasks affect the detection of explanation obstacles and, subsequently, the generation of explanation questions concerning scientific texts. These three elements, reading tasks, obstacle detection and question asking, are closely interrelated. Reading tasks influence the type of mental representation attempted by readers. Attempted mental representations, in turn, are a key element in defining the comprehension obstacles found, and these obstacles influence the questions asked. These elements are analysed in the next section.

\section{Reading tasks and discourse representation}

Given a particular text, the immediate goal of a reader consists of constructing an internal representation of discourse appropriate for the attempted task. Many text comprehension models distinguish at least three levels in this representation: surface structure, textbase or situation model (Graesser, Millis, and Zwaan 1997; Kintsch 1998; Van Dijk and Kintsch 1983). The surface structure is the most basic level of representation. It preserves the text's exact wording and syntax, but is quickly forgotten, whilst the meaning is preserved (Kintsch et al. 1990). The representation of meaning in a propositional form corresponds to the second level of representation: the textbase. The textbase captures the meaning of the explicit text. The third level, the situation model, is a representation of the situation described by the text. It includes text information and also knowledge retrieved from the reader's memory.

Questions on texts may be conceived of as attempts to overcome obstacles in order to construct the desired mental representation of discourse (Otero 2009). These obstacles may appear when subjects try to construct a representation of discourse at any level (Otero and Graesser 2001; Yuill and Oakhill 1991). A reader may encounter obstacles in building up a basic representation of explicit text meanings, i.e. a textbase. A question such as What does asphyxia mean? may be understood as an attempt to remove a lexical obstacle that blocks a reader who tries to construct such a basic representation of a text on breathing. However, readers also usually attempt mental representations at situation model level, and questions may be asked to overcome the new obstacles found. A reader may want to represent the temporal or spatial circumstances of a described event as a part of a situation model, namely how it develops, what causes it or what its consequences are. If this information is not provided in the text, the reader may try to solve these obstacles to satisfactory representation by asking When $\mathrm{X}$ ? Where $\mathrm{X}$ ? How $\mathrm{X}$ ? Why $\mathrm{X}$ ? What happens next?

In the following, we assume competent readers with substantial knowledge of the text content. Therefore, their mental representations will not consist of a textbase only, since they are also expected to construct a representation of discourse at situation model level. Obstacles may be encountered during the attempt and, given the appropriate social conditions (Graesser and McMahen 1993), questions may be asked to overcome these obstacles.

Readers' tasks in educational settings, and the goals associated to these tasks, may be varied. Students may read a paragraph to understand it well enough to answer the teacher's questions, they may read a statement to solve a vocabulary 
problem, or they may read written instructions to perform an experiment in the laboratory. These various tasks and associated reading goals influence the discourse representation that students attempt to construct and are a determinant of text comprehension (van den Broek et al. 2001). For instance, it has been found that reading for recall vs. reading to perform an action facilitates the creation of a textbase vs. a situation model representation, respectively (Kintsch 1994; Mills et al. 1995; Schmalhofer and Glavanov 1986).

\section{Reading to understand vs. reading to perform an experiment}

The discourse representations that the students participating in this experiment were expected to construct were manipulated by instructing them to carry out two different tasks: reading to understand a procedural text vs. reading to perform a procedure described by a text. Different discourse representations would be expected in each of the two situations. When reading for understanding, causal relations are a particularly important component of the mental representation. This expectation is supported in general by models such as the constructionist theory of discourse comprehension by Graesser, Singer, and Trabasso (1994): generating explanations of why events occur is an essential component of text comprehension. Readers are active seekers of meaning who try to explain the events mentioned in a text. Numerous studies have demonstrated the importance of causal or goal-based explanations in the mental representation of narratives (Klin 1995; Suh and Trabasso 1993; Trabasso and Suh 1993; van den Broek 1990), and also in expository texts (Coté, Goldman, and Saul 1998; Millis and Graesser 1994; Singer and Gagnon 1999; Wiley and Myers 2003). Therefore, as a reflection of the importance of causal, explanatory relations in the mental representation of a scientific text, a high incidence of explanation obstacles would be expected when a student reads in order to understand a passage describing a natural phenomenon or scientific device. This is what Ishiwa, Sanjosé, and Otero (2013) precisely found in experiments that provided a background for the present study. They analysed the influence of reading goals on the mental representation of short science passages, such as the ones used in this study, and on question generation. Ishiwa, Sanjosé, and Otero (2013) specifically examined the inferences made and the obstacles identified by students who read the passages in an understanding condition (to take a comprehension test) or, alternatively, in a problem-solving condition (to solve the problem described by the passage). A robust result of the study was a significantly greater frequency of explanatory obstacles identified in the understanding condition compared to the problem-solving condition. This was linked to the finding of a greater frequency of explanatory inferences in the understanding condition also, as expected.

A different mental representation and different obstacles would be expected when reading in order to perform a procedure. Reading about a physical system in order to carry out an experiment involves attempting a representation in which objects and processes are elaborated in sufficient detail to predict how the system operates (Norman 1983). Explanatory inferences and causal relations may be important if they are relevant to the workings of the procedure, but there is no need otherwise to include them in the representation. In addition, some school practical work is frequently considered by students as mainly manipulative and relatively devoid of theoretical content (Abrahams and Millar 2008). Students in traditional laboratories focus on manipulative activities, paying less attention to the ideas that 
provide meaning and relevance for the events taking place in the laboratory. If this interpretation is correct, more explanation obstacles and explanation questions would be expected in the understanding condition than in an experiment condition that mirrors the typical, traditional classroom experiment work. Alternatively, should the student participants conceive of the laboratory task as an activity involving true inquiry, there would be no reason to expect less concern for explanations.

In order to test these hypotheses, a sample of secondary school students was provided with procedural texts to be read under the two previously described conditions: understanding or experimenting. In the understanding condition, the participants were told to read two short passages so that they could answer a comprehension test in the next class. In the experimenting condition, they had to read the same passages in order to carry out the experiments described in the passages, in the next class also. The students were instructed to write down any questions they found necessary because these would be answered before taking the comprehension test or doing the experiments. The dependent variable of interest was the number of explanation questions asked under the two conditions. This study focuses on explanation obstacles and explanation questions, although the students were expected to ask other types of questions also. In the study mentioned above, Ishiwa, Sanjosé, and Otero (2013) used two additional categories of obstacles. "Association" obstacles address the need to adequately represent the entities of the system under consideration, and are frequently formulated as who, what, how, when and where questions. "Prediction" obstacles relate to difficulties in generating predictive inferences and are frequently formulated as what happens next or what if questions. The significant differences in explanation obstacles found by Ishiwa, Sanjosé, and Otero (2013) suggest limiting the aim of our study to examine explanation obstacles in another instructionally relevant condition, namely reading in order to perform a science experiment.

\section{Method \\ Subjects}

Twenty-six 12th grade students (approximately 18-year old) from a Portuguese public school located in an area of medium socio-economic status took part in the study. All the students were enrolled on a physics course and had taken science courses in the four previous years (physics, chemistry, biology and geology). A 0-20 scoring scale was used in this course. Twenty-one students had final scores between 16 and 20 and the remaining five had scores between 10 and 15 . Therefore, the class was considered to be comprised of fairly good science students.

\section{Materials}

Two procedural passages on physical phenomena that could be reproduced in a laboratory were used (Table 1 shows the English translations). One passage provided a brief explanation of the Cartesian Diver (143 words, in the Portuguese version), a phenomenon which, in the opinion of the teachers, was expected to be surprising for most of the students. It involved causal relations that were not expected to be understood immediately by the participants. The passage was organised into two paragraphs. The first described the device and the second provided a brief explanation of how it worked. 
Table 1. Texts used in the study.

The Cartesian Diver

Submarines explore the ocean depths, both by floating and diving down to the ocean bed

To understand how they work, a toy invented by Descartes, the Cartesian Diver, may be used. It can be made with a plastic pen cap and a piece of plasticine. The Cartesian Diver is put into a plastic bottle filled almost to the top with water, so that it can float with the top of the cap above the water. Care must be taken to ensure the cap does not have a hole in it and the amount of plasticine needed to make the Cartesian Diver float must be tested in a glass of water. If the bottle is corked well, when the sides are pressed the Cartesian Diver will dive to the bottom. To make it come up again, the pressure on the bottle simply has to be released

A physicist would explain that a body can float whenever its weight balances the buoyant force acting on it. As this force is equal to the weight of the displaced fluid, it diminishes slightly when the bottle is pressed because the excess pressure reduces the air pumped inside the cap. Thus, its weight is now greater than the buoyant force and the diver sinks to the bottom. It can be concluded from this that the Cartesian Diver only sinks when its weight exceeds the buoyant force

\section{Ethanol Gun}

The "Ethanol Gun" (a gun containing pure alcohol) can be used to understand how cannons function. The "Ethanol Gun" is prepared by piercing each side of a strong bottle (for e.g. a juice bottle) with a long iron nail. The ends of the two nails must be exactly $0.6 \mathrm{~m}$ apart and there must be nothing between them. About $1 \mathrm{ml}$ of ethanol is poured into the bottle and shaken thoroughly. The bottle is then sealed with a wellfitting cork. Next, the bottle is securely fixed to a support, with its mouth turned slightly upwards. Using an electric lighter a spark is directed towards the end of one of the nails piercing the bottle. A noisy explosion occurs and the cork is projected to the other side of the room

A chemist would explain that an explosion is produced because a combustion reaction occurs inside the bottle. The combustion is an exothermic reaction of the ethanol with oxygen from the air, caused by the spark. It is clear that the combustion increases the pressure inside the bottle, since the reaction substantially increases the temperature. This explains why the cork is shot out like a cannon ball

The other passage, the Ethanol Gun, which was 192 words long in the original Portuguese version, also involved an unusual phenomenon and was expected to encourage questioning as well. It was also organised into two paragraphs, the first describing the phenomenon and the second providing a short explanation.

Both passages deal with phenomena whose base is included in the Portuguese science curriculum for the 12 th year and previous years. The topic of buoyant force involved in the explanation of the Cartesian Diver phenomenon had been studied by the student participants in the 12th year physics course and in other science courses in previous years. The background explanation for the phenomena described in the Ethanol Gun passage is included in the chemistry curriculum from the 8 th the 12 th year.

\section{Procedure}

The class teacher presented the tasks as part of the classroom activity. The students were randomly assigned to the two conditions, understanding or experiment. They were provided with the booklets that included the two experimental passages describing the devices, and different written instructions depending on the reading 
condition. In the understanding condition, the task was presented as a reading comprehension exercise that would be followed by a comprehension test on the passages in the next class, without involving any laboratory activity. In the experiment condition, the task was presented as part of a laboratory exercise and the students were instructed to read the passages so that they could construct the devices and carry out the experiments in the next class. In both the conditions, they were advised to write down any questions they had on the passages in the space provided. These questions would be answered before the next class. The instructions stated that the passages would not be available to answer the comprehension test or to carry out the experiment in the next class.

The students read the passages during one normal class session of $50 \mathrm{~min}$. The whole procedure took about $20 \mathrm{~min}$. At the end of the session they were debriefed and the teacher announced that there would not be a second session, although she did answer the students' questions.

\section{Measurements}

Explanation questions were identified by looking for question stems such as "Why ...?" or "How is it that ...", a frequent Portuguese expression used to ask for an explanation. These two stems were included in $38 \%$ of the explanation questions. The remaining $62 \%$ corresponded to other formulations which, in the view of the researchers, expressed explanation questions. These included questions using causal verbs such as "to cause" (How does the spark at the outer end of the nail cause combustion?) or "to make" (What makes the cap sink?).

In order to check for reliability, two of the authors categorised a subset of 60 questions, resulting in a Kappa coefficient of intercoder agreement of 0.98 .

\section{Results}

The students asked a total of 81 questions in the understanding condition and 58 of these $(71.6 \%)$ were explanation questions. There were 53 questions asked in the experiment condition and $31(58.5 \%)$ were explanation questions. Table 2 shows descriptive statistics for the explanation questions asked per student on each of the two passages in the two experimental conditions.

To examine differences in the count variable "explanation questions", and given the small number of observations available, we have used non-parametric Mann-Whitney tests to examine differences between task conditions, and Wilcoxon matched-pairs signed-ranks tests to examine differences between passages. The total number of explanation questions asked per student was significantly greater in the understanding condition than in the experimenting condition $(U=42.00, p=0.028)$.

Table 2. Descriptive statistics for explanation questions asked on the passages in each experimental condition (standard deviations and ranges in parentheses).

\begin{tabular}{|c|c|c|c|c|}
\hline & \multicolumn{2}{|c|}{ Understanding } & \multicolumn{2}{|c|}{ Experimenting } \\
\hline & $M$ & Mdn & $M$ & Mdn \\
\hline Cartesian Diver & $2.36(1.08)$ & $2.5(1-4)$ & $1.75(0.75)$ & $2.0(0-3)$ \\
\hline Ethanol Gun & $1.79(0.98)$ & $2.0(1-3)$ & $0.83(1.03)$ & $0.5(0-3)$ \\
\hline
\end{tabular}


When considering the passages separately, this difference was non-significant for the Cartesian Diver passage $(U=56.50, p=0.138)$ and significant for the Ethanol Gun passage $(U=42.50, p=0.026)$. The difference in the number of explanation questions per student between passages was non-significant in the understanding condition $(Z=-1.71, p=0.087)$ and significant in the experimenting condition $(Z=-2.50, p=0.013)$.

\section{Discussion}

The main purpose of this experiment was to test for the effect of an understanding task vs. an experiment task on explanation obstacles and explanation questions. The results led to three main conclusions. First, the explanation obstacles found by students depended on the reading tasks considered. According to the questions asked, readers were sensitive to explanation obstacles when they tried to understand the passages in order to prepare for a comprehension test, and significantly less so when they pursued a practical goal, such as performing the experiment described by them. The fact that the understanding task was particularly demanding of explanations is in line with results from other studies on student questioning. In an experiment by Costa et al. (2000), secondary school students were instructed to read short scientific passages and to ask any questions that might help them understand the passages. A categorisation of the questions in the 18-item taxonomy of Graesser, Person, and Huber (1992) showed an overwhelming majority of causal antecedent questions. The students reading under an understanding condition were especially sensitive to the comprehensibility of causal relations and were able to detect many difficulties in these causal relations.

Furthermore, the importance of explanation obstacles when students read scientific texts for understanding is consistent with the results obtained from studies on inferencing. Causal antecedent inferences, aimed at explaining why events occur, are frequently found to be generated when readers try to understand scientific texts (Graesser and Bertus 1998; Millis and Graesser 1994). Therefore, a scientific text presenting events that are difficult to relate causally obstructs the generation of causal inferences and should be a source of explanation obstacles and corresponding explanation questions.

A final, additional implication of the importance of explanation obstacles in understanding tasks concerns how students conceive of an understanding task. Students engage in school activities, such as reading, often without being conscious of the learning goal they are pursuing (Bereiter and Scardamalia 1989). Reading in order to understand scientific texts may be one of these ill-defined activities, given the vagueness that the term "understanding" has, even for experts (Graesser, Singer, and Trabasso 1994; Kintsch 1994). The results of this study suggest that, for these students, understanding basically involves a concern for explanations and not, for instance, a concern to predict the behaviour of systems. Understanding amounts to "causally explaining" to a great extent. In contrast, reading about the same phenomena in order to carry out traditional laboratory work does not involve such an important concern for explanations.

The second main conclusion pertains to the effect of the experiment task. The fact that fewer overall explanation questions were asked in the experiment condition is consistent with studies showing the lack of effectiveness of traditional laboratory work with regard to the conceptual understanding of science. Many students do not 
know why they do laboratory work beyond following prescribed procedures (Abrahams and Millar 2008; Hart et al. 2000; Hodson 1991). Therefore, asking for explanations on the phenomena involved in the experiment would be of limited concern to the students, who probably believed that they were involved in a traditional experimental task.

The third main conclusion concerns the difference found between the passages. The experiments showed that text influences the number of explanation questions asked. The difference in explanation questions between task conditions was significant for the Ethanol Gun passage only. Although the difference for the Cartesian Diver passage was in the expected direction, it did not reach significance. Also, there were significantly more explanation questions asked on the Cartesian Diver passage than on the Ethanol Gun passage in the experimenting condition. Although we kept the same structure in the two passages, they may differ in terms of important parameters affecting the explanation obstacles found by students. The content of our passages involved subject matter amply treated in the curricula of the student participants. However, the readers' actual knowledge of the specific content and various features of the passages may interact in complex ways and influence the obstacles detected and the questions produced. A study of such interactions was well beyond the limits of our work, but would be a worthwhile project for future studies.

Two additional limitations of the study should be mentioned at this point. In the first place, we had a small sample size and limited information about students' personal characteristics. Additional research on this topic would require larger samples, and more precise measurements of individual variables such as students' ability. A second limitation of our study was the absence of a final measure of understanding and experimentation. The significant increase of explanation obstacles in the understanding condition compared to the experimenting condition would be expected to have a correspondence with understanding measures. Ishiwa, Sanjosé, and Otero (2013) found such a correspondence in a situation in which short scientific texts were read for understanding or, alternatively, to solve a simple problem. A greater number of explanation obstacles in the understanding condition compared to the problem-solving condition were found to correspond to a greater number of explanatory inferences made in the former condition compared to the latter. More explanatory inferences result in deeper understanding of the target texts. Future studies may test the correspondence between questioning and outcome measures in conditions of understanding and experimenting, examining the relation between the number of explanation questions and measurements of understanding and of performance in carrying out the experiments.

\section{Acknowledgements}

This work is funded by FEDER, through the Programa Operacional Factores de Competitividade-COMPETE and by National funds through FCT-Fundação para a Ciência e Tecnologia in the frame of project PTDC/CPE-CED/105546/2008 and by grant EDU2008-05359-C02-01 of the Ministry of Education, Spain.

\section{Notes on contributors}

Júlia Morgado (MSc) is a school physics teacher in Tomar (Portugal), teaching at lower and upper secondary levels. Her MSc thesis focused on pupils questioning about science texts. She has been involved in research projects on this topic and on science learning processes. 
José Otero is an emeritus professor of science education at the University of Alcalá. He has published on science text comprehension, comprehension monitoring and question asking. $\mathrm{He}$ is currently interested in the psychological and educational roles of ignorance.

Piedade Vaz-Rebelo is an assistant professor of educational sciences at the Faculty of Science and Technology of the University of Coimbra. She specialises in teacher education and her research focuses on teaching and learning processes and their interactions with school, family and personal variables.

Vicente Sanjosé is a professor of science education at the Department of Science Education of the University of Valencia. He has involved in several teacher training programmes, and his research focuses on science comprehension, problem-solving, comprehension monitoring and question asking.

Helena Caldeira is a professor at the Department of Physics of the Faculty of Science and Technology of the University of Coimbral, and the deputy director of the interactive science centre "Exploratório Infante D. Henrique". She has done extensive research on physics teaching and learning at the secondary and university level.

\section{References}

Abrahams, I., and R. Millar. 2008. "Does Practical Work Really Work? A Study of the Effectiveness of Practical Work as a Teaching and Learning Method in School Science." International Journal of Science Education 30 (14): 1945-1969.

Alexander, P. A., J. M. Kulikowich, and S. K. Schulze. 1994. "The Influence of Topic Knowledge, Domain Knowledge and Interest on the Comprehension of Scientific Exposition." Learning and Individual Differences 6: 379-397.

Bereiter, C., and M. Scardamalia. 1989. "Intentional Learning as a Goal of Instruction." In Knowing, Learning, and Instruction: Essays in Honor of Robert Glaser, edited by L. B. Resnick, 361-392. Hillsdale, NJ: Lawrence Erlbaum Associates.

Brincones, I., and J. Otero. 1994. "Student's Conceptions of the Top-Level Structure of Physics Texts." Science Education 78: 171-183.

Costa, J., H. Caldeira, J. R. Gallástegui, and J. Otero. 2000. “An Analysis of Question asking on Scientific Texts Explaining Natural Phenomena." Journal of Research in Science Teaching 37: 602-614.

Coté, N., S. Goldman, and E. U. Saul. 1998. "Students Making Sense of Informational Text: Relations between Processing and Representation." Discourse Processes 25: 1-53.

Dee-Lucas, D., and J. H. Larkin. 1990. "Organization and Comprehensibility in Scientific Proofs: Or, 'Consider a Particle P...'.’ Journal of Educational Psychology 82: 701-714.

Dunlosky, J., and J. Metcalfe. 2008. Metacognition. San Francisco, CA: Sage.

Graesser, A. C., and E. Bertus. 1998. "The Construction of Causal Inferences while Reading Expository Texts on Science and Technology." Scientific Studies of Reading 2: 247-269.

Graesser, A. C., J. A. León, and J. Otero. 2002. "Introduction to the Psychology of Science Text Comprehension." In The Psychology of Science Text Comprehension, edited by J. Otero, J. A. León, and A. Graesser, 1-15. Mahwah, NJ: Lawrence Erlbaum Associates.

Graesser, A. C., and C. L. McMahen. 1993. "Anomalous Information Triggers Questions When Adults Solve Quantitative Problems and Comprehend Stories." Journal of Educational Psychology 85: 136-151.

Graesser, A. C., K. K. Millis, and R. A. Zwaan. 1997. "Discourse Comprehension." Annual Review of Psychology 48: 163-189.

Graesser, A. C., N. K. Person, and J. D. Huber. 1992. "Mechanisms that Generate Questions." In Questions and Information Systems, edited by T. Lauer, E. Peacock, and A. C. Graesser, 167-187. Hillsdale, NJ: Lawrence Erlbaum Associates.

Graesser, A. C., M. Singer, and T. Trabasso. 1994. "Constructing Inferences during Narrative Text Comprehension." Psychological Review 101: 371-395.

Hart, C., P. Mulhall, A. Berry, J. Loughran, and R. Gunstone. 2000. "What is the Purpose of this Experiment? Or can Students Learn Something from Doing Experiments?” Journal of Research in Science Teaching 37: 655-675. 
Hodson, D. 1991. "Practical Work in Science: Time for a Reappraisal." Studies in Science Education 19: 175-184.

Ishiwa, K., V. Sanjosé, and J. Otero. 2013. "Questioning and Reading Goals: InformationSeeking Questions asked on Scientific Texts Read under Different Task Conditions." British Journal of Educational Psychology 83: 502-520.

Kintsch, W. 1994. "Text Comprehension, Memory, and Learning." American Psychologist 49: 294-303.

Kintsch, W. 1998. "The Representation of Knowledge in Minds and Machines." International Journal of Psychology 33: 411-420.

Kintsch, W., D. Welsch, F. Schmalhofer, and S. Zimny. 1990. "Sentence Memory: A Theoretical Analysis." Journal of Memory and Language 29: 133-159.

Klin, C. M. 1995. "Causal Inferences in Reading: From Immediate Activation to Long-Term Memory." Journal of Experimental Psychology: Learning, Memory and Cognition 21: 1483-1494.

Millis, K., and A. Graesser. 1994. "The Time-Course of Constructing Knowledge-Based Inferences for Scientific Texts." Journal of Memory and Language 33: 583-599.

Mills, C. B., V. A. Diehl, D. P. Birkmire, and L. Mou. 1995. "Reading Procedural Texts: Effects of Purpose for Reading and Predictions of Reading Comprehension Models." Discourse Processes 20: 79-107.

Norman, D. 1983. "Some Observations on Mental Models." In Mental Models, edited by D. Gentner and A. L. Stevens, 7-14. Hillsdale, NJ: Lawrence Erlbaum Associates.

Otero, J. 2009. "Question Generation and Anomaly Detection in Texts." In Handbook of Metacognition in Education, edited by D. Hacker, J. Dunlosky, and A. Graesser, 47-59. New York: Routledge.

Otero, J., and A. Graesser. 2001. "PREG: Elements of a Model of Question Asking." Cognition and Instruction 19: 143-175.

Ozuru, Y., K. Dempsey, and D. McNamara. 2009. "Prior Knowledge, Reading Skill, and Text Cohesion in the Comprehension of Science Texts." Learning and Instruction 19: 228-242.

Schmalhofer, F., and D. Glavanov. 1986. "Three Components of Understanding a Programmer's Manual: Verbatim, Propositional, and Situational Representations." Journal of Memory and Language 25: 279-294.

Singer, M., and N. Gagnon. 1999. "Detecting Causal Inconsistencies in Scientific Text." In Narrative Comprehension, Causality, and Coherence: Essays in Honor of Tom Trabasso, edited by S. R. Golman, A. Graesser, and P. van den Broek, 179-194. Mahwah, NJ: Lawrence Erlbaum Associates.

Snow, C. 2002. Reading for Understanding: Toward a R\&D Program in Reading Comprehension. Santa Monica, CA: RAND Corporation.

Suh, S. Y., and T. Trabasso. 1993. "Inferences During Reading: Converging Evidence from Discourse Analysis, Talk-Aloud Protocols, and Recognition Priming." Journal of Memory and Language 32: 279-300.

Thiede, K. W., J. Wiley, and T. D. Griffin. 2011. "Test Expectancy affects Metacomprehension Accuracy." British Journal of Educational Psychology 81: 264-273.

Trabasso, T., and S. Suh. 1993. "Understanding Text: Achieving Explanatory Coherence through On-Line Inferences and Mental Operations in Working Memory." Discourse Processes 12: 1-25.

van den Broek, P. 1990. "Causal Inferences and the Comprehension of Narrative Texts." Psychology of Learning and Motivation 25: 175-196.

van den Broek, P., R. F. Lorch, T. Linderholm, and M. Gustafson. 2001. "The Effects of Readers' Goals on Inference Generation and Memory for Texts." Memory \& Cognition 29: 1081-1087.

Van Dijk, T. A., and W. Kintsch. 1983. Strategies of Discourse Comprehension. New York: Academic Press.

Wiley, J., and J. L. Myers. 2003. "Availability and Accessibility of Information and Causal Inferences from Scientific Text." Discourse Processes 36: 109-129.

Yuill, N., and J. Oakhill. 1991. Children's Problems in Text Comprehension. Cambridge: Cambridge University Press. 